\title{
In Focus
Spotlight on the September 10 Issue
}

\author{
Robert A. Gross, MD, PhD, FAAN \\ Editor-in-Chief, Neurology ${ }^{\circledR}$
}

Migraine prevalence, socioeconomic status, and social causation

The authors showed that the inverse relationship of migraine prevalence with household income was largely explained by the influence of income on migraine onset, but not by disease duration. Identifying factors associated with low socioeconomic status that influence migraine onset is a crucial step toward preventive interventions.

See p. 948

From editorialists Peterlin \& Scher: “...the current findings go a long way in providing evidence that social causation plays an important role in the association between episodic migraine and income, and provide important insights and direction for future research."

See p. 942

Protein array-based profiling of CSF identifies RBPJ as an autoantigen in multiple sclerosis

IgG in CSF of persons with multiple sclerosis was examined with a microarray targeting 9,393 proteins. A target antigen, RBPJ, was identified and validated in an independent cohort of samples by ELISA and immunocytochemistry, indicating that particular autoantibody profiles need to be defined for disease stages and pathologic processes to be utilized in a clinical setting.

See p. 956; Editorial, p. 944

Physical activity is related to the structural integrity of cerebral white matter

Four hundred forty individuals with cerebral small-vessel disease had MRI. The cross-sectional relation between physical exercise and microstructural integrity of the white matter was assessed by applying Tract-Based Spatial Statistics to diffusion tensor imaging measures. In patients at risk for dementia, physical exercise was related to connections in the brain that indicated greater white matter integrity. See p. 971

\section{Neuropathologic basis of white matter hyperintensity} accumulation with advanced age

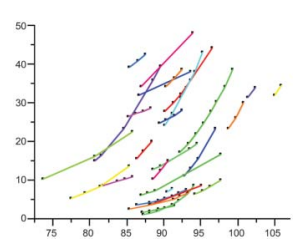

In 66 individuals followed until death, greater accumulation of white matter disease was associated with high amounts of neurofibrillary tangles (NFTs) and arteriolosclerosis at autopsy, and high amounts of atherosclerosis were observed in those with high NFT burdens. This link

between neurodegenerative disease and cerebrovascular disease may indicate strategies to reduce the risk of cognitive decline.

See p. 977

Podcasts can be accessed at www.neurology.org

Relations of arterial stiffness and endothelial function to brain aging in the community

In models with risk factors for vascular and brain disease, greater aortic stiffness was associated with smaller total cerebral brain volume, higher white matter hyperintensity volume, higher prevalence of silent cerebral infarcts, and Alzheimer-type memory deficits. Interventions preventing aortic stiffening with advancing age may delay the onset of cognitive impairment.

See p. 984

Dose dependence of fetal malformations associated with valproate

The specific type of fetal malformations in offspring exposed to valproate in utero was correlated with the dose of valproate taken by the mother in the first trimester. Human fetal malformations associated with valproate exposure during pregnancy did not seem to bear the same quantitative relationship to drug dose.

See p. 999

SPECIAL ARTICLE

The American Academy of Neurology's Top Five Choosing Wisely recommendations :0

This AAN work group identified its Top Five recommendations of tests and procedures not to perform in headache, multiple sclerosis, imaging, and stroke. The AAN's involvement will not end with this publication as there will be future opportunities to update and develop additional neurologic recommendations.

See p. 1004; Editorial, p. 946; see also p. 1022

NB: "The case of the locked house: The unfinished mystery," see p. 1018. This final case written by Dr. Joynt was unfinished when he passed away, so the ending will be written by a coauthor. To check out other Reflections submissions written by Dr. Joynt, point your browser to www.neurology.org. 


\section{Neurology}

Spotlight on the September 10 Issue

Robert A. Gross

Neurology 2013;81;941

DOI 10.1212/WNL.0b013e3182a6702e

This information is current as of September 9, 2013

\section{Updated Information \&} Services

Permissions \& Licensing

Reprints including high resolution figures, can be found at: http://n.neurology.org/content/81/11/941.full

Information about reproducing this article in parts (figures,tables) or in its entirety can be found online at:

http://www.neurology.org/about/about_the_journal\#permissions

Information about ordering reprints can be found online:

http://n.neurology.org/subscribers/advertise

Neurology ${ }^{\circledR}$ is the official journal of the American Academy of Neurology. Published continuously since 1951, it is now a weekly with 48 issues per year. Copyright @ 2013 American Academy of Neurology. All rights reserved. Print ISSN: 0028-3878. Online ISSN: 1526-632X.

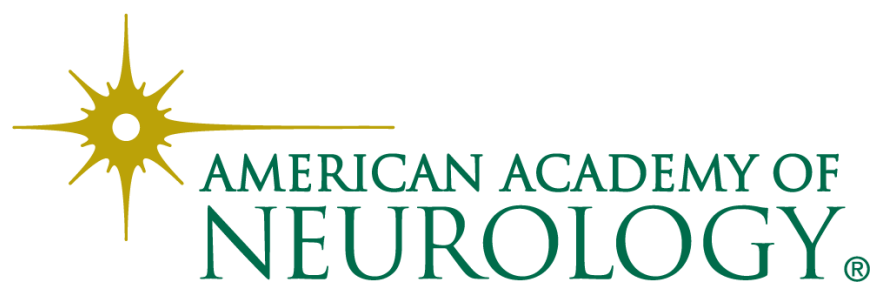

